\title{
In situ proliferation and differentiation of macrophages in dental pulp
}

\author{
Yukikatsu Iwasaki • Hirotada Otsuka • Nobuaki Yanagisawa • Hisashi Hisamitsu • \\ Atsufumi Manabe $\cdot$ Naoko Nonaka $\cdot$ Masanori Nakamura
}

Received: 14 February 2011 /Accepted: 24 July 2011 /Published online: 16 September 2011

(C) The Author(s) 2011. This article is published with open access at Springerlink.com

\begin{abstract}
The presence of macrophages in dental pulp is well known. However, whether these macrophages proliferate and differentiate in the dental pulp in situ, or whether they constantly migrate from the blood stream into the dental pulp remains unknown. We have examined and compared the development of dental pulp macrophages in an organ culture system with in vivo tooth organs to clarify the developmental mechanism of these macrophages. The first mandibular molar tooth organs from ICR mice aged between 16 days of gestation (E16) to 5 days postnatally were used for in vivo experiments. Those from E16 were cultured for up to 14 days with or without $10 \%$ fetal bovine
\end{abstract}

Part of this study was supported by Grant-in-Aid for Scientific Research $(21592342,20592148)$ from the Ministry of Education, Culture, Sports, Science, and Technology of Japan. This study was also supported in part by the High-Tech Research Center Project for Private Universities from the Ministry of Education, Culture, Sports, Science, and Technology, Japan.

Y. Iwasaki $\cdot$ H. Otsuka $\cdot$ N. Yanagisawa $\cdot$ N. Nonaka $\cdot$

M. Nakamura $(\bowtie)$

Department of Oral Anatomy and Developmental Biology,

Showa University School of Dentistry,

1-5-8 Hatanodai, Shinagawa-ku,

Tokyo 142-8555, Japan

e-mail:masanaka@dent.showa-u.ac.jp

Y. Iwasaki $\cdot$ H. Hisamitsu $\cdot$ A. Manabe

Department of Clinical Cariology,

Showa University School of Dentistry,

1-5-8 Hatanodai, Shinagawa-ku,

Tokyo 142-8555, Japan

Y. Iwasaki • H. Hisamitsu • A. Manabe

Department of Aesthetic Dentistry,

Showa University School of Dentistry,

1-5-8 Hatanodai, Shinagawa-ku,

Tokyo 142-8555, Japan serum. Dental pulp tissues were analyzed with immunohistochemistry to detect the macrophages and with reverse transcription and the polymerase chain reaction (RT-PCR) for the detection of factors related to macrophage development. The growth curves for the in vivo and in vitro cultured cells revealed similar numbers of F4/80-positive macrophages in the dental pulp. RT-PCR analysis indicated the constant expression of myeloid colony-stimulating factor (M-CSF) in both in-vivo- and in-vitro-cultured dental pulp tissues. AntiM-CSF antibodies significantly inhibited the increase in the number of macrophages in the dental pulp. These results suggest that (1) most of the dental pulp macrophages proliferate and differentiate in the dental pulp without a supply of precursor cells from the blood stream, (2) M-CSF might be a candidate molecule for dental pulp macrophage development, and (3) serum factors might not directly affect the development of macrophages.

Keywords Dental pulp - Immunohistochemistry . Macrophage $\cdot$ M-CSF . Organ culture $\cdot$ Mouse (ICR)

\section{Introduction}

Macrophages are a heterogenous population of cells, characterized by their morphology, function, and metabolism. At least two types of macrophages are distributed in the body: resident and exudative macrophages (Daems and Brederoo 1972). Whereas exudative macrophages migrate into sites of inflammation in response to several chemokines, resident macrophages are ubiquitously distributed around the body under normal healthy conditions (Daems and Brederoo 1973; Daems et al. 1976, 1979; Soranzo et al. 1978; Daems and van der Rhee 1980). According to the concept of the mononuclear phagocyte system (van Furth et 
al. 1972), both these types of macrophages are derived from blood monocytes, which originate in the bone marrow. Furthermore, macrophages are generally accepted to be relatively short-lived cells and do not show any proliferative activity (van Furth 1975, 1980, 1989, 1992). However, several recent studies have demonstrated the in situ proliferation of resident macrophages in various tissues in response to several cytokines, such as myeloid colonystimulating factors (GM-CSF and M-CSF), secreted into the proliferation microenvironment (Naito et al. 1996; Sawa et al. 2003; Douglass et al. 2008).

Large numbers of macrophages exist in the dental pulp and are considered to be the major immunocompetent cells that fight against bacterial infections caused by dental caries (Nakakura-Ohshima et al. 2003; Zhang et al. 2006). In reality, macrophages migrate toward the infection site in pulpitis. However, whether dental pulp macrophages proliferate and differentiate in situ, or whether monocytes derived from the circulation differentiate into macrophages remains uncertain.

The tissue organ culture system is commonly used to examine the development of the tooth organ (Fujiwara 1997; Fujiwara et al. 2005). Our previous studies have indicated that 2 days of development in culture is almost equal to 1 day of in vivo development, and that the calcification of dentin and enamel can be detected following culture under either serum-supplemented or serumless conditions (Evans et al. 1988; Nakamura et al. 1994). In the system presented here, the migration of blood monocytes from the circulation can be excluded, because of the isolation of tooth organs from the mandibles.

In this study, we have used immunohistochemistry to examine the number and phenotype of macrophages in in-vivo- and in-vitro-cultured dental pulp as a product of time in order to determine whether these cells proliferate and differentiate in situ. We have also used reverse transcription with the polymerase chain reaction (RT-PCR) to analyze the possible factors responsible for the proliferation and differentiation of these macrophages.

\section{Materials and methods}

The experimental protocol used in this study was reviewed and approved by the Animal Care Committee of Showa University.

Mice

Pregnant ICR mice were purchased from Sankyo Laboratory Service (Tokyo, Japan) and maintained under routine conditions at the Laboratory Animal Center of Showa University. Mandibular first molars taken from mice aged from 16 days of gestation (E16) to 5 days postnatally $(5 \mathrm{dPN})$ were examined.

Organ culture

E16 mandibular first molar tooth organs were dissected and maintained for up to 14 days in a Tronwell culture system with serum-supplemented or a serumless, chemically defined medium as previously described (Evans et al. 1988; Nakamura et al. 1994). The explants were placed on $0.2-\mu \mathrm{m}$ pore-size Millipore filter discs (Bedford, Mass., USA) and supported by stainless steel mesh triangles. The explants were cultured in Grobstein Falcon dishes under optimal humidity conditions in an atmosphere containing $5 \% \mathrm{CO}_{2}$ and $95 \%$ air. The medium used was Fitton-Jackson modified BGJb medium (Sigma, St. Louis, Mo., USA), with or without $10 \%$ FBS (fetal bovine serum), and supplemented with $100 \mathrm{mM}$ ascorbic acid, $100 \mathrm{U} / \mathrm{ml}$ penicillin, and $100 \mathrm{mg} / \mathrm{ml}$ streptomycin. The medium (pH 7.4 at the start of each culture) was changed every other day.

To examine the inhibitory effect of M-CSF on the development of dental pulp resident macrophages, a neutralizing antibody against M-CSF (R \& D Systems, Abingdon, Berkshire, UK) was added to the culture medium at a final concentration of $16 \mu \mathrm{g} / \mathrm{ml}$. For control experiments, isotype-matched rat IgG2b (eBioscience, Burlingame, Calif., USA) was added to the medium at the same concentration.

\section{Tissue preparation}

Mandibles from E16 to $5 \mathrm{dPN}$ mice and first molar tooth organs cultured for 2-14 days were fixed with $4 \%$ paraformaldehyde in $0.01 \mathrm{M}$ phosphate-buffered saline (PBS) at $\mathrm{pH}$ 7.4. After decalcification with $10 \%$ EDTA, specimens were immersed in 5\%,15\%, and 30\% sucrose, embedded in Tissue-Tek O.C.T Compound (Sakura Finetek USA, Torrance, USA), and snap-frozen in a mixture of acetone and dry ice for analysis by immunohistochemistry. Sections $(10 \mu \mathrm{m}$ thick) were processed for hematoxylin and eosin staining and immunohistochemistry.

\section{Antibodies}

Four markers were applied in this study for the identification of macrophage-lineage cells in the dental pulp: F4/80, CD68, ER-MP20, and ER-MP58. F4/80 is usually used as the marker for resident macrophages, whereas CD68 is a marker of macrophage activation (Leenen et al. 1994; Dambach et al. 2002; Lloyd et al. 2008). ER-MP20 and ER-MP58 are both used as markers for monocytic progenitor cells (Leene et al. 1990, 1994; Chan et al. 
1998; Kennedy and Abkowitz 1998). Proliferating cell nuclear antigen (PCNA) was used as a proliferation marker (Hillmeister et al. 2008; Vassiliou et al. 2010).

Anti-F4/80, CD68, ER-MP20 (Ly-6C), ER-MP58, and PCNA monoclonal antibodies were purchased from SEROTEC (Oxfordshire, UK). Goat anti-rat IgG antibodies, conjugated with either Alexa Fluor 488 or Alexa Fluor 594, were purchased from Molecular Probes (Eugene, Ore., USA). Biotinylated goat anti-rat IgG antibody was purchased from VECTOR (Burlingame, Calif., USA).

Immunohistochemical procedures

Frozen sections (10 $\mu \mathrm{m}$ thick) were cut from the embedded tissues, placed on poly-L-lysine-coated glass slides, and airdried. After incubation in $0.3 \% \mathrm{H}_{2} \mathrm{O}_{2}$-methanol for $30 \mathrm{~min}$, the sections were incubated with $5 \%$ normal goat serum in PBS containing $5 \%$ bovine serum albumin and $0.025 \%$ Triton X-100, followed by incubation with each of the monoclonal antibodies. After several rinses, the sections were incubated with biotinylated goat anti-rat $\operatorname{IgG}$ antibody and then with an avidin-biotin-bound horseradish peroxidase complex. After being washed, the sections were incubated with a mixture of 3,3'-diaminobenzidine tetrahydrochloride $\left(0.5 \mathrm{mg} / \mathrm{ml}\right.$; WAKO, Osaka, Japan) and $\mathrm{H}_{2} \mathrm{O}_{2}$ at a final concentration of $0.03 \%$ in $0.1 \mathrm{M}$ TRIS-HCl buffer at $\mathrm{pH}$ 7.6. Counterstaining was achieved with methyl green. As controls, sections were incubated with either normal rat serum or PBS instead of the primary antibody. After the immunolabeling step, the number of F4/80-, CD68-, ER-MP20-, and ER-MP58-positive cells in the dental pulp was counted $(100 \times 100 \mu \mathrm{m})$.

For the double-labeling of F4/80- and CD68- or ERMP20-positive macrophages, sections were first incubated with the F4/80 antibody and then with the Alexa-Fluor-488conjugated goat anti-rat IgG antibody. After being washed, sections were incubated with anti-CD68 or anti-ER-MP20 antibody and then with Alexa-Fluor-594-conjugated goat anti-rat $\mathrm{IgG}$ antibody.

For the double-labeling of PCNA- and F4/80-positive macrophages, sections were first boiled with antigen retrieval buffer (10 mM sodium citrate, $\mathrm{pH}$ 6.0) for $10 \mathrm{~min}$ before the sections were incubated with anti-mouse-PCNA mouse monoclonal antibody (BD Biosciences Pharmingen, San Diego, Calif., USA) and then with Alexa-Fluor-488conjugated goat anti-mouse $\operatorname{IgG}$ antibody. After being washed, sections were incubated with anti-F4/80 antibody and then with Alexa-Fluor-594-conjugated goat anti-rat IgG antibody. After several washes with PBS, sections were mounted with AquaMount (Polysciences, Warrington, Pa., USA) and observed with a Nikon ECLIPSE 50i fluorescent microscope (Tokyo, Japan).
RT-PCR analysis

The in vivo and in vitro cultured mandibular first molar tooth organs were homogenized after the careful removal of enamel organs under a dissection microscopy. Total RNA was extracted from each sample by using an RNeasy Mini kit (QIAGEN, Tokyo, Japan). A total of 4 mg RNA served as a template for RT-PCR, which was performed by means of an Gene Amp Gold RNA PCR (Applied Biosystems, Tokyo, Japan) with mG-CSF, mGM-CSF, and mM-CSF sequence-aligned primers. The primers used for PCR analysis were as follows: GM-CSF forward, 5'-GCG TGA CAT TAA AGA AGC TG-3'; reverse, 5'-CTC AGG AGG AGC AAT GAT CTT G-3'; G-CSF forward, 5'-GGG ACA AGA CAT CCC TGT TT-3'; reverse, 5'-CTG TGA GGA CAG GAA ACC CT-3'; M-CSF forward, 5'-CTA GGG GCC AGC ATT AGA CC-3'; reverse, 5'-GAC ACA TAC TAC ACC CCA GAG G-3'; and beta-actin forward, 5'GCG TGA CAT TAA AGA GAA GCT G-3'; reverse, 5'CTC AGG AGG AGC AAT GAT CTT G-3'. Amplification conditions were as follows: the RT reaction was performed at $25^{\circ} \mathrm{C}$ for $10 \mathrm{~min}$ and at $42^{\circ} \mathrm{C}$ for $12 \mathrm{~min}$; the PCR started at $95^{\circ} \mathrm{C}$ for $10 \mathrm{~min}$, followed by 30 cycles consisting of a denaturing step at $95^{\circ} \mathrm{C}$ for $20 \mathrm{~s}$, an annealing step at $60^{\circ} \mathrm{C}$ for $1 \mathrm{~min}$, and an extension step at $72^{\circ} \mathrm{C}$ for $2 \mathrm{~min}$. Final extension took place at $72^{\circ} \mathrm{C}$ for $7 \mathrm{~min}$. PCR products were mixed with $10 \times$ loading buffer (TAKARA BIOTECHNOLOGY, Shiga, Japan) at the ratio $10: 1(\mathrm{v} / \mathrm{v})$ and were separated by electrophoresis at $100 \mathrm{~V}$ for $30 \mathrm{~min}$ on a $1.0 \%$ agarose gel.

\section{Statistical analyses}

Statistical significance was evaluated by using the Student's unpaired $t$-test or Mann-Whitney $\mathrm{U}$ test, for which $P$ values of $<0.01$ were considered significant.

\section{Results}

Immunohistochemical detection of resident macrophages in dental pulp during in vivo development

In the dental pulp of the first mandibular molar tooth organ at age E16, dental pulp cells adjacent to the basement membrane became polarized, whereas no dentin matrix was secreted at this time (Fig. 1a). A small number of F4/80-, ER-MP20- (Ly- 6C), and ER-MP58-positive cells were detected, whereas CD68-positive cells were not detected at this stage (Fig. 1e, i, m, q). At OdPN, dental pulp cells beneath the basement membrane differentiated into odontoblasts and secreted dentin matrix (Fig. 1b). F4/80- and ERMP20-positive cells were observed throughout the dental 

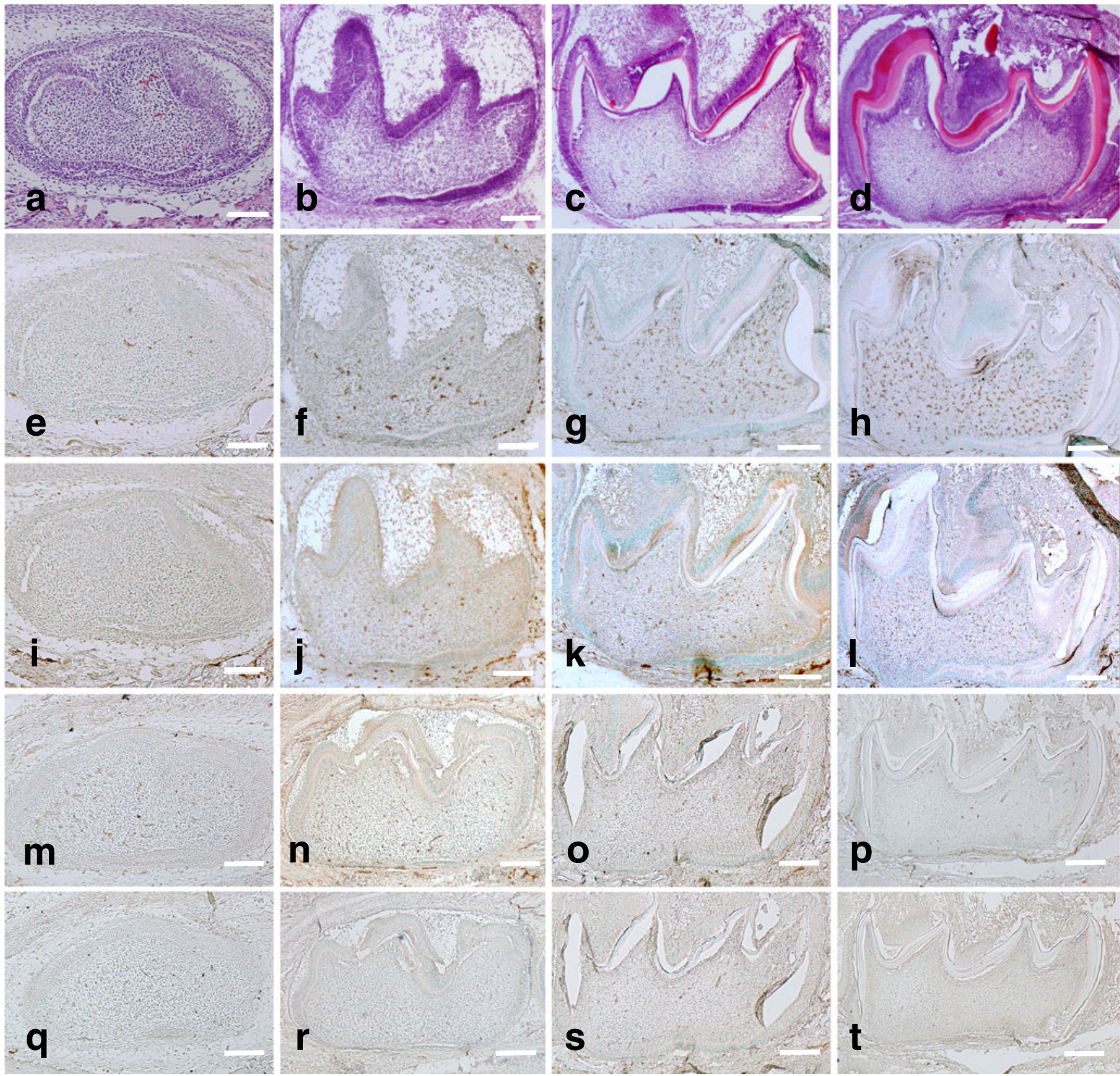

Fig. 1 In vivo development of mouse mandibular first molars at E16 $(\mathbf{a}, \mathbf{e}, \mathbf{i}, \mathbf{m}, \mathbf{q}), 0 \mathrm{dPN}(\mathbf{b}, \mathbf{f}, \mathbf{j}, \mathbf{n}, \mathbf{r}), 3 \mathrm{dPN}(\mathbf{c}, \mathbf{g}, \mathbf{k}, \mathbf{o}, \mathbf{s})$, and $5 \mathrm{dPN}(\mathbf{d}, \mathbf{h}$, $\mathbf{l}, \mathbf{p}, \mathbf{t})$. Hematoxylin and eosin (H-E) staining indicated the development of tooth organs (a-d). Immunohistochemical detection

of F4/80-positive cells (e-h), CD68-positive cells (i-l), ER-MP20positive cells $(\mathbf{m}-\mathbf{p})$, and ER-MP58-positive cells $(\mathbf{q}-\mathbf{t})$ indicated an increase in the number of macrophages with tooth organ development. Bars $100 \mu \mathrm{m}$

pulp (Fig. 1f, n), and CD68- and ER-MP58-positive cells were also detected at this stage (Fig. 1j, r). During this development, the odontoblasts secreted more dentin matrix and formed calcified dentin (Fig. 1c, d). Inner enamel epithelial cells differentiated into secretory ameloblasts and formed enamel (Fig. 1c, d).

The number of F4/80- and CD68-positive cells increased significantly with development (Fig. 1g, h, k, l; see also quantitation below). In contrast, the number of ER-MP20-

and ER-MP58-positive cells decreased or were constant at a low level (Fig. 1o, p, s, t; see also quantitation below). At all of the developmental stages, the number of CD68positive cells was lower than that of the F4/80-positive cells (see quantitation below).

These results suggest that the macrophages actively proliferate within the dental pulp, even if a relatively low number of monocytes might penetrate from the bloodstream. 
Immunohistochemical detection of resident macrophages in in-vitro-cultured dental pulp

First mandibular molar tooth organs taken from mice aged E16 were used for organ culture. When cultured in serumsupplemented media, tooth organs developed with time. By 6 days, odontoblasts secreted dentin matrix (Fig. 2a), and the formation of dentin and enamel proceeded at 10 and 14 days (Fig. 2b, c). The number of F4/80-positive cells increased significantly during development (Figs. 2d-f, 3b). CD68-positive cells were detected from 6 days of culture, and the number of these cells increased significantly during development (Figs. 2g-i, 3c). ER-MP20- and ER-MP58positive cells decreased significantly during development (Figs. 2j-o, 3d, e). The number of F4/80-positive cells was always higher than that of the CD68-positive cells (Fig. 3b, c).
The same results were obtained from the organ culture experiments in the serumless, chemically defined media condition (Fig. 3b, c). No significant differences were detected between the numbers of F4/80- and CD68-positive cells under either of the two culture conditions (Fig. 3b, c). The number of these cells in vivo was higher than the organ culture tooth organ cells (Fig. 3a-c).

The organ culture results strongly support the possibility of the direct proliferation of macrophages within the dental pulp and also indicate the lack of contribution from serum factors for macrophage development.

\section{Double-immunostaining of macrophages}

Double-staining of the macrophages with the anti-F4/80 and anti-CD68 antibodies in vivo and in vitro showed that
Fig. 2 Development of E16 mouse mandibular first molars in organ culture under serumsupplemented conditions for 6 days (a, $\mathbf{d}, \mathbf{g}, \mathbf{j}, \mathbf{m}), 10$ days $(\mathbf{b}, \mathbf{e}, \mathbf{h}, \mathbf{k}, \mathbf{n})$, and 14 days (c, f, i, l, o). H-E staining indicated the development of tooth organs (a-c). Immunohistochemical detection of F4/80-positive cells (d-f), CD68-positive cells (g-i), ER-MP20-positive cells ( $\mathbf{j}-\mathbf{l})$, and ER-MP58-positive cells $(\mathbf{m}-\mathbf{0})$ indicated an increase in the number of macrophages with tooth organ development. Bar $100 \mu \mathrm{m}$
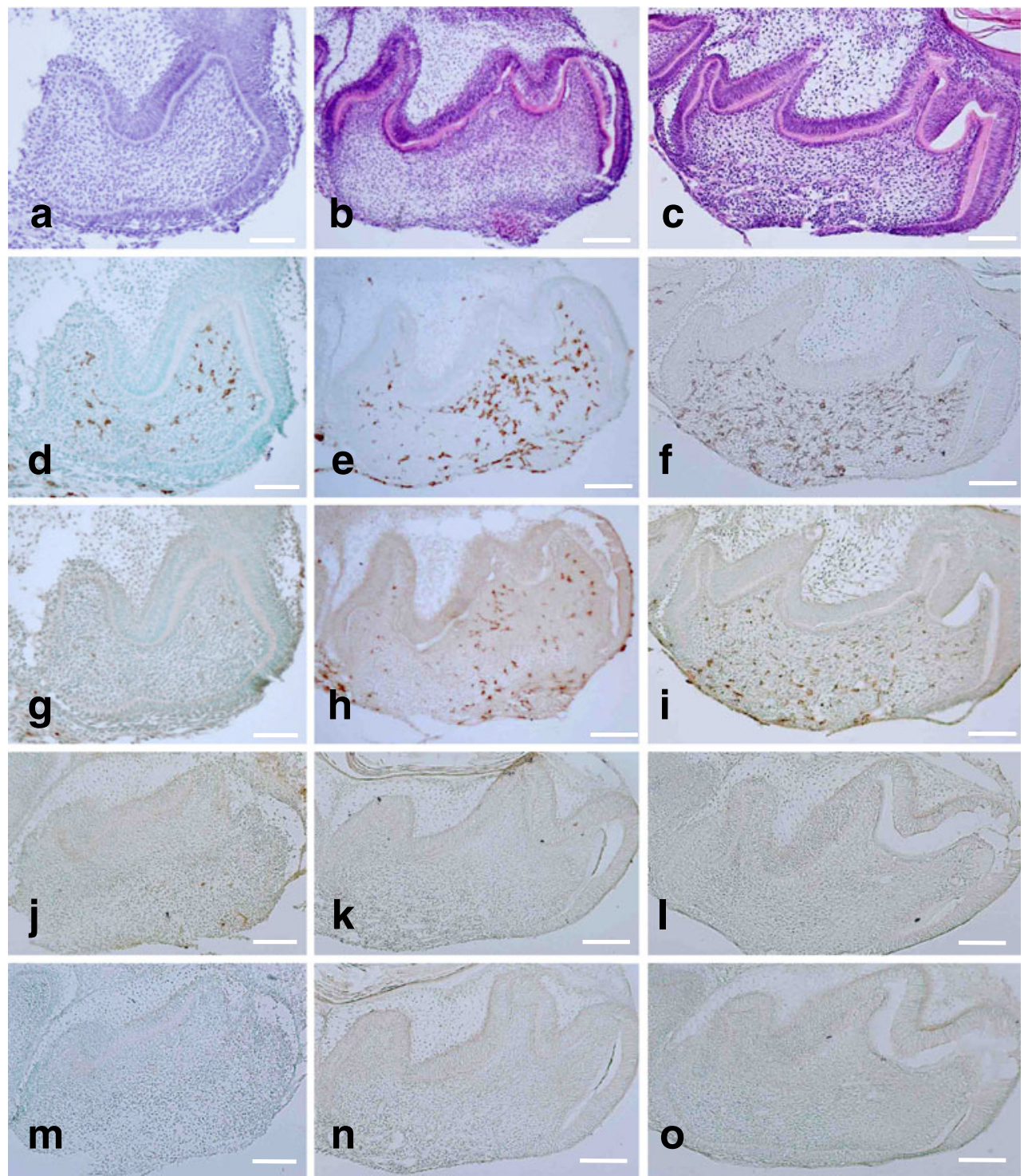

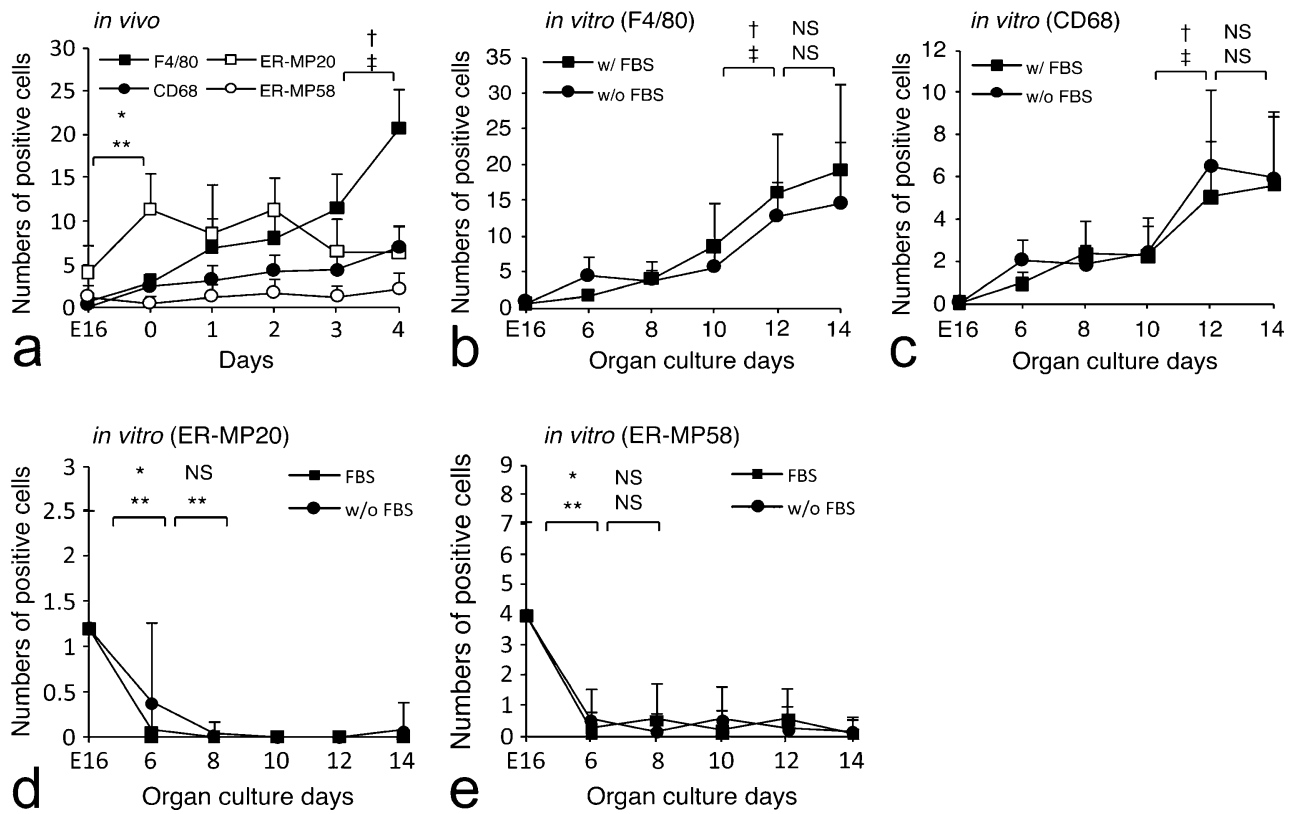

Fig. 3 Numbers of F4/80-, CD68-, ER-MP20-, and ER-MP58positive cells in dental pulp with development. Data are representative of means $\pm \mathrm{SD} ; P$ values of $<0.01$ were considered to be significant. a In vivo development of F4/80-, CD68-, ER-MP20-, and ER-MP58positive cells. b Development of F4/80-positive cells in organ culture with or without fetal bovine serum $(w / F B S, w / o$ FBS $)$. c Development of CD68-positive cells in organ culture with or without fetal bovine

all CD68-positive cells were also F4/80-positive, whereas the F4/80 single-positive cells were distributed throughout the dental pulp (Fig. 4c, f). Most of the macrophages were relatively large and had well-developed cell processes (Fig. 4a-f).

Double-staining of the macrophages with anti-F4/80 and anti-ER-MP20 antibodies in vivo and in vitro showed that all F4/80-positive cells were also ERMP20-positive at age E16 (Fig. 4g-i). During development, the number of F4/80 single-positive cells increased, whereas the number of ER-MP20 single-positive cells decreased. As a result, the number of double-positive cells decreased (Figs. 3a, d, 4j-r).

These results suggest that immature ER-MP20-positive cells present in the interstitial area within the dental pulp differentiate into F4/80-positive cells via the ER-MP20 and F4/80 double-positive developmental stage.

Double-immunostaining of macrophages with anti-F4/80 and anti-PCNA antibodies

As the results from the in vivo and in vitro immunostaining strongly suggested the direct proliferation of F4/80-positive cells within the dental pulp, we next examined the expression of PCNA in F4/80-positive cells. Double- serum ( $w / F B S$, w/o FBS). d Development of ER-MP20-positive cells in organ culture with or without fetal bovine serum ( $w / F B S, w / o F B S)$. e Development of ER-MP58-positive cells in organ culture with or without fetal bovine serum $(w / F B S, w / o F B S) .{ }^{*} P<0.01$, $\uparrow$ : in vivo $(F 4 / 80)$, in vitro $(w / F B S),+$ : in vivo $(C D 68)$, in vitro (w/o FBS), *: in vivo (ER-MP20), in vitro $(w / F B S),{ }^{*}$ : in vivo (ER-MP58), in vitro (w/o $F B S) ; N S$ not significant

staining of macrophages with anti-F4/80 and anti-PCNA antibodies in vivo and in vitro revealed that some of the F4/ 80-positive cells were also PCNA-positive (Fig. 5), which indicated that the F4/80-positive cells were proliferating within the peripheral dental pulp.

\section{RT-PCR analysis of dental pulp}

Next, we examined the factors relating to the development of macrophages in the dental pulp. The expression of three cytokines important for leukocyte development (G-CSF, GM-CSF, and M-CSF) was examined by RT-PCR (Fig. 6). Among these three cytokines, the high expression of $\mathrm{M}$ CSF was detected constitutively during the examined period in both in vivo and in vitro dental pulp cells. The expression of GM-CSF was detected at all of the examined times, although this expression was not stable. G-CSF was also expressed constantly during the developmental period.

Effects of M-CSF-neutralizing antibody on macrophage development in dental pulp

Finally, we examined the effect of M-CSF on macrophage development in dental pulp by means of the organ culture system. The addition of anti-M-CSF in the culture medium 
Fig. 4 Double-immunostaining of dental pulp macrophages with anti-F4/80 (a, d) and antiCD68 (b, e) antibodies in 4dPN $(\mathbf{a}-\mathbf{c})$ and 14-day-cultured tooth organs $(\mathbf{d}-\mathbf{f})$. All

CD68-positive cells were F4/80-positive (c, f). Doubleimmunostaining of dental pulp macrophages with anti-F4/80 $(\mathbf{g}, \mathbf{j}, \mathbf{m}, \mathbf{p})$ and anti-ER-MP20 $(\mathbf{h}, \mathbf{k}, \mathbf{n}, \mathbf{q})$ antibodies in E16 (g-i), 3dPN (j-l), 8-day (m-o), and 14-day-cultured tooth organs (p-r). Bar $25 \mu \mathrm{m}$
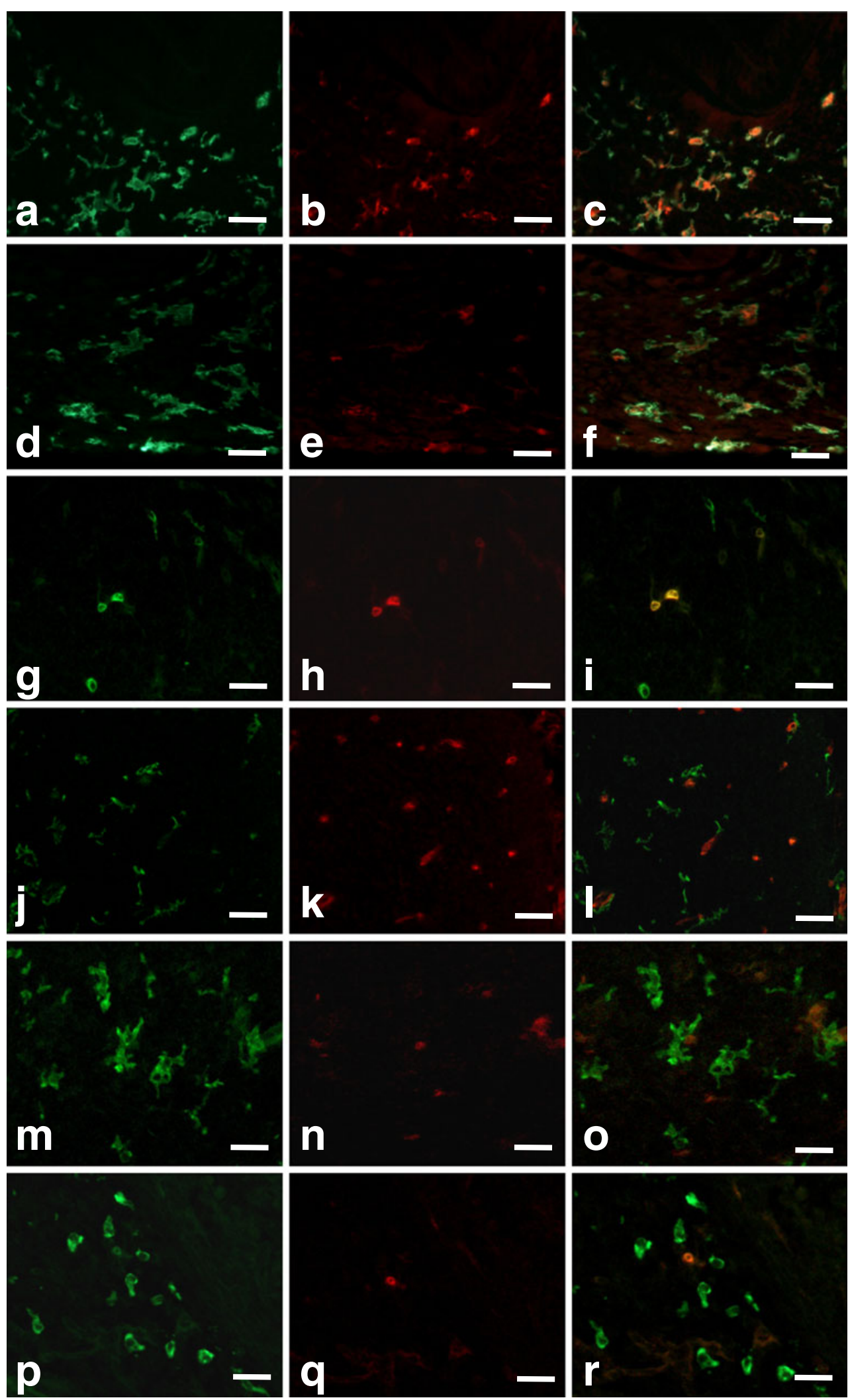

O
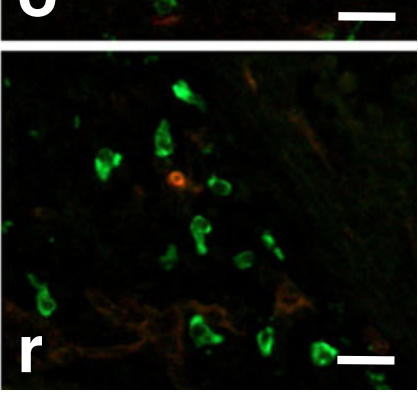

resulted in a significant reduction of F4/80-positive and CD68-positive cells in the dental pulp compared with the isotype matched control at day 12 of culture $(P<0.01$;
Fig. 7). No obvious developmental defects could be detected in the tooth organs following the addition of the antibody (data not shown). 
Fig. 5 Double-immunostaining of dental pulp macrophages with anti-PCNA $(\mathbf{a}, \mathbf{d})$ and anti-F4/80 (b, e) antibodies in $4 \mathrm{dPN}(\mathbf{a}-\mathbf{c})$ and 8-day-cultured tooth organs $(\mathbf{d}-\mathbf{f})$. All PCNApositive cells were $\mathrm{F} 4 / 80$ positive (c, f). Bar $25 \mu \mathrm{m}$
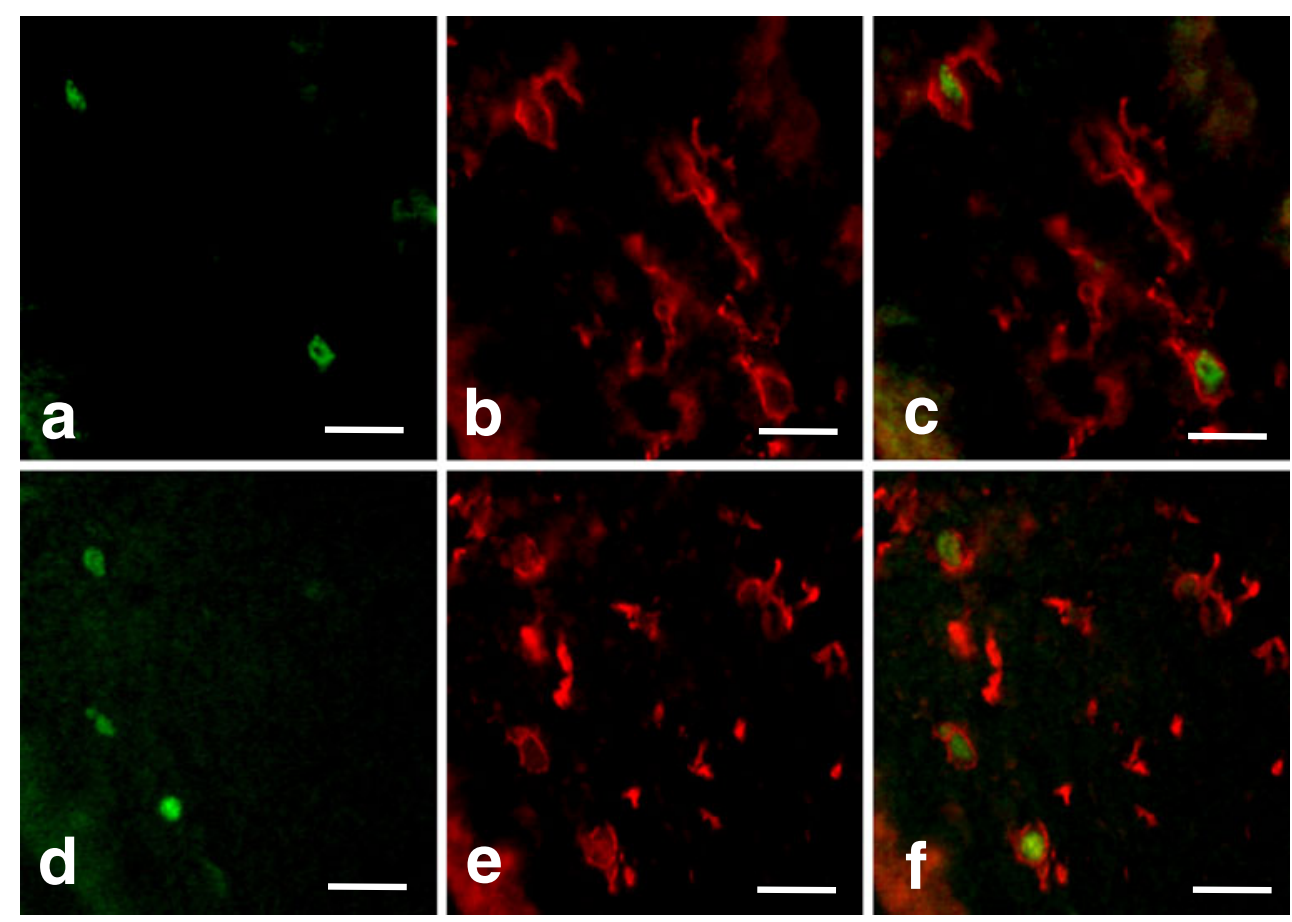

\section{Discussion}

In this study, we used the tooth organ culture system to examine the proliferation of macrophages within the dental pulp. For cultivation, tooth organs were isolated from the mandibles, a procedure that resulted in the exclusion of a blood monocyte invasion from the circulation. In the tooth organ culture system, the number of macrophages in the dental pulp increased during organ development. At age E16, the dental pulp contained a few F4/80-positive macrophages. Even if these F4/80-positive cells had migrated into the dental pulp from the bloodstream as monocytes, our results provide direct evidence that the macrophages proliferate in the dental pulp in situ.

The number of macrophages was always higher in vivo than in vitro. As blood vessels were developed in the dental pulp of in vivo tooth organs, the monocytes must have migrated from the blood stream into the dental pulp. This environmental difference might explain the difference between the number of macrophages observed under the two conditions. However, the number of ER-MP20-positive cells gradually decreased during development. In contrast, the number of F4/80-positive macrophages increased during development. Furthermore, under the in vivo and
Fig. 6 RT-PCR analysis of the expression of M-CSF, GM-CSF, $\mathrm{G}-\mathrm{CSF}$, and $\beta$-actin in dental pulp of in vivo and organ culture with or without fetal bovine serum $(w / F B S, w / o F B S)$
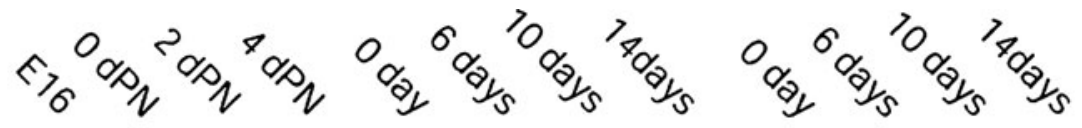

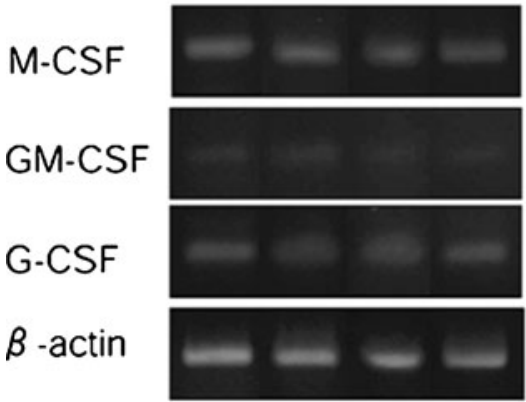

in vivo
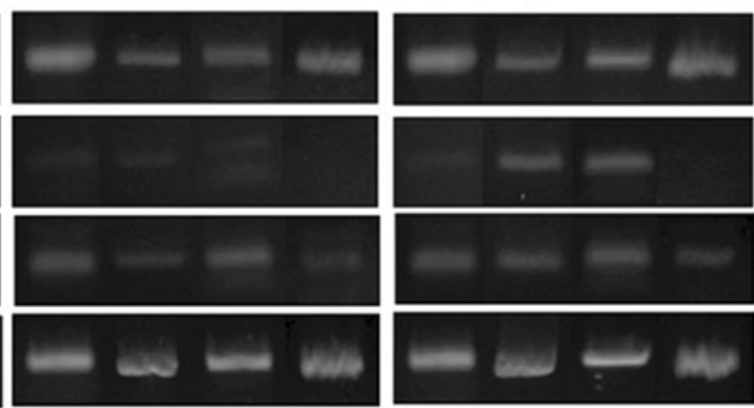

in vitro (w/FBS)

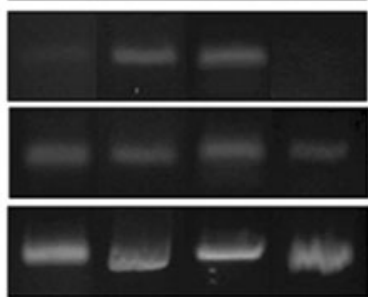

in vitro (w/o FBS) 


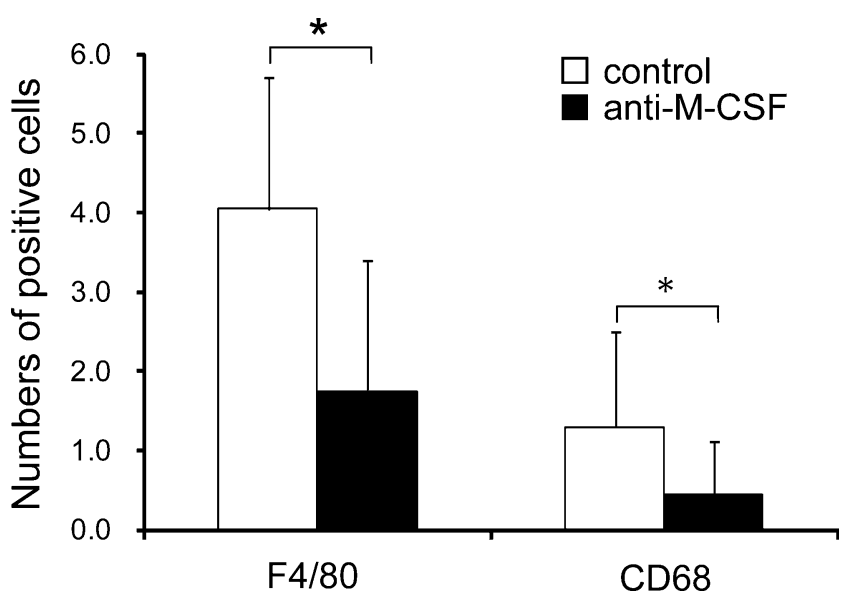

Fig. 7 Effects of the M-CSF neutralizing antibody on the development of macrophages in dental pulp. The number of F4/80- and CD68-positive cells was significantly decreased by the addition of the antibody to the medium. Data are representative of means \pm SD. ${ }^{*} P$ values of $<0.01$ were considered to be significant

in vitro culture conditions, F4/80-positive macrophages were also PCNA-positive, and the number of F4/80positive cells was always higher than the CD68-positive cells. These results strongly imply that, even if a small number of macrophages is supplied from the blood stream, most of the F4/80-positive macrophages in the dental pulp represent a self-proliferating population that is distinct from the monocyte population and that develops into functionally activated CD68-positive cells in situ.

Several studies have suggested that macrophages proliferate in various organs. During ontogeny, primitive macrophages develop, proliferate, and differentiate into fetal macrophages before the production of monocytes in the fetal hematopoietic tissues (Naito and Wisse 1977; Naito et al. 1986, 1989, 1990, 1991; Takahashi et al. 1989; Higashi et at. 1992). Yamamoto et al. (2008) have identified macrophages in osteopetrotic (op/op) mice. These animals contain approximately half the number of macrophages found in healthy animals. Resident macrophages are capable of proliferating under various experimental conditions (Wisse 1974; Widmann and Fahimi 1975; Hibbs et al. 2007). In mice that have been rendered monocytopenic following the administration of strontium-89 (Yamada et al. 1990; Naito and Takahashi 1991), the number of Kupffer cells is maintained by the proliferation of resident Kupffer cells.

The production of monocytes and macrophages is controlled by various cytokines, such as interleukin-6 (IL-6), IL-3, GM-CSF, and M-CSF. Among these, M-CSF is the most important key molecule for mediating the development and differentiation of a restricted macrophage lineage belonging to the mononuclear phagocyte system and for the production of heterogeneous macrophage populations (Rutherford et al.
1993; Naito et al. 1996; Douglass et al. 2008). Moreover, M-CSF has been reported to stimulate the growth of macrophages, and resident macrophages exist in the local tissues, such as the Kupffer cells in the liver, microglial cells in the brain, mesangial cells in the kidney, and osteoclasts in bone (Takashima et al. 1995; Douglass et al. 2008). M-CSFderived macrophages are larger in size, develop more abundant intracellular organelles, and extend more welldeveloped cell processes than GM-CSF-derived and IL-3derived macrophages (Morioka et al. 1994).

The macrophages detected in the dental pulp in this study were also large and extended several cell processes. RT-PCR analysis also revealed the constitutive expression of M-CSF mRNA in the dental pulp, as previously indicated by Sawa et al. (2003). The lack of F4/80-positive resident macrophages in the dental pulp was furthermore indicated in osteopetrotic (op/op) mice, which carried an M-CSF mutation (Nagahama et al. 1998). Neutralizing antibodies against M-CSF significantly inhibited the proliferation of resident macrophages in the dental pulp in our study. Tooth organs developed in an organ culture system in both serum-supplemented and serum-less conditions. Under both conditions, the number of F4/80-positive cells increased similarly. These results indicate that M-CSF is the main cytokine responsible for the development of resident macrophages in the dental pulp.

Macrophages in the dental pulp are considered to be one of the major types of immunocompetent cells that fight dental pulp infections. Several studies have mentioned the possibility of resident macrophages being involved in the regulatory function and differentiation of odontoblasts (Ohshima et al. 1995; Tsuruga et al. 1999; NakakuraOhshima et al. 2003). However, the precise functions of the macrophages in the dental pulp have not yet been clarified. According to Zhang et al. (2006), two types of cells with well-developed cell processes exist in the dental pulp: the CD11c-positive sentinel and F4/80-positive interstitial cells. The CD11c-positive cells constitutively express toll-like receptors 2 and 4 and displayed high migration activities. They rapidly move to the infected regions in the dental pulp and then migrate into the local lymph nodes. In contrast, F4/80-positive cells exhibit low migration activity. Therefore, CD11c-positive cells and F4/80-positive cells are considered to be sentinel and interstitial cells, respectively. In our study, we have not examined the further phenotypic characterization of resident macrophages. Whether these cells show the same phenotypic and functional characterizations in vivo and in vitro remains undetermined and should be considered in future investigations.

In conclusion, our in vivo and in vitro studies indicate that dental pulp macrophages proliferate and differentiate in situ. The main factor involved in the development of these macrophages might be M-CSF. 
Open Access This article is distributed under the terms of the Creative Commons Attribution Noncommercial License which permits any noncommercial use, distribution, and reproduction in any medium, provided the original author(s) and source are credited.

\section{References}

Chan J, Leenen PJ, Bertoncello I, Nishikawa SI, Hamilton JA (1998) Macrophage lineage cells in inflammation: characterization by colony-stimulating factor-1 (CSF-1) receptor (c-Fms), ER-MP58, and ER-MP20 (Ly-6C) expression. Blood 92:1423-1431

Daems WT, Brederoo P (1972) The fine structure and peroxidase activity of resident and exudate peritoneal macrophages in the guinea pig. Adv Exp Med Biol 15:19-31

Daems WT, Brederoo P (1973) Electron microscopical studies on the structure, phagocytic properties, and peroxidatic activity of resident and exudate peritoneal macrophages in guinea pigs. $\mathrm{Z}$ Zellforsch Mikrosk Anat 144:247-297

Daems WT, Rhee HJ van der (1980) Peroxidase and catalase in monocytes, macrophages, epithelioid cells and giant cells of the rat. In: Furth $\mathrm{R}$ van (ed) Mononuclear phagocytes, functional aspects, Part I. Nijhoff, The Hague, pp 43-60

Daems WT, Koerten HK, Soranzo MR (1976) Differences between monocyte-derived and tissue macrophages. Adv Exp Med Biol 73:27-40

Daems WT, Roos D, Berkel TJC van, Rhee HJ van der (1979) The subcellular distribution and biochemical properties of peroxidase in monocytes and macrophages. In: Dingle JT, Jacques PJ (eds) Lysosomes in biology and pathology, vol 6. North-Holland, Amsterdam, pp 463-516

Dambach DM, Watson LM, Gray KR, Durham SK, Laskin DL (2002) Role of CCR2 in macrophage migration into the liver during acetaminophen-induced hepatotoxicity in the mouse. Hepatology 35:1093-1103

Douglass TG, Driggers L, Zhang JG, Hoa N, Delgado C, Williams CC, Dan Q, Sanchez R, Jeffes EWB, Wepsic HT, Myers MP, Koths K, Martin R, Jadus MR (2008) Macrophage colony stimulating factor: not just for macrophages anymore! A gateway into complex biologies. Int Immunopharmacol 10:1354-1376

Evans J, Bringas P Jr, Nakamura M, Nakamura E, Santos V, Slavkin HC (1988) Metabolic expression of intrinsic developmental programs for dentine and enamel biomineralization in serumless, chemically-defined, organotypic culture. Calcif Tissue Int $42: 220-230$

Fujiwara N (1997) In vitro formation of cementum in mouse molar germs cultured in newly developed organ culture system. Jpn J Oral Biol 39:143-154

Fujiwara N, Tabata MJ, Endoh M, Ishizeki K, Nawa T (2005) Insulinlike growth factor-I stimulates cell proliferation in the outer layer of Hertwig's epithelial root sheath and elongation of the tooth root in mouse molars in vitro. Cell Tissue Res 320:69-75

Furth R van (1975) Modulation of monocyte production. In: Furth R van (ed) Mononuclear phagocytes in immunity, infection, and pathology. Blackwell Scientific, Oxford, pp 161-172

Furth R van (1980) Cells of the mononuclear phagocyte system. Nomenclature in terms of sites and conditions. In: Furth $\mathrm{R}$ van (ed) Mononuclear phagocytes, functional Aspects. Nijhoff, The Hague, pp 1-30

Furth R van (1989) Origin and turnover of monocytes and macrophages. Curr Top Pathol 79:125-147

Furth R van (1992) Production and migration of monocytes and kinetics of macrophages. In: Furth $\mathrm{R}$ van (ed) Mononuclear phagocytes. Biology of monocytes and macrophages. Kluwer Academic, Dordrecht, pp 3-12
Furth R van, Cohn ZA, Hirsch JG, Humphrey JH, Spector WG, Langevoort HL (1972) The mononuclear phagocyte system: a new classification of macrophages, monocytes, and their precursor cells. Bull World Health Organ 46:845-852

Hibbs ML, Quilici C, Kountouri N, Seymour JF, Armes JE, Burgess AW, Dunn AR (2007) Mice lacking three myeloid colony-stimulating factors (G-CSF, GM-CSF, and M-CSF) still produce macrophages and granulocytes and mount an inflammatory response in a sterile model of peritonitis. J Immunol 178:6435-6443

Higashi K, Naito M, Takeya M, Ando M, Araki S, Takahashi K (1992) Ontogenetic development, differentiation, and phenotypic expression of macrophages in fetal rat lungs. J Leukoc Biol $51: 444-454$

Hillmeister P, Lehmann KE, Bondke A, Witt H, Duelsner A, Gruber C, Busch HJ, Jankowski J, Ruiz-Noppinger P, Hossmann KA, Ivo R, Buschmann IR (2008) Induction of cerebral arteriogenesis leads to early-phase expression of protease inhibitors in growing collaterals of the brain. J Cereb Blood Flow Metab 28:1811-1823

Kennedy DW, Abkowitz JL (1998) Mature monocytic cells enter tissues and engraft. Proc Natl Acad Sci USA 95:14944-14949

Leenen PJ, Melis M, Slieker WA, Ewijk W van (1990) Murine macrophage precursor characterization. II. Monoclonal antibodies against macrophage precursor antigens. Eur J Immunol 20:27-34

Leenen PJ, Bruijn MF de, Voerman JS, Campbell PA, Ewijk W van (1994) Markers of mouse macrophage development detected by monoclonal antibodies. J Immunol Methods 174:5-19

Lloyd CM, Phillips AR, Cooper GJ, Dunbar PR (2008) Three-colour fluorescence immunohistochemistry reveals the diversity of cells staining for macrophage markers in murine spleen and liver. J Immunol Methods 334:70-81

Morioka Y, Naito M, Sato T, Takahashi K (1994) Immunophenotypic and ultrastructural heterogeneity of macrophage differentiation in bone marrow and fetal hematopoiesis of mouse in vitro and in vivo. J Leukoc Biol 55:642-651

Nagahama SI, Cunningham ML, Lee MY, Byers MR (1998) Normal development of dental innervation and nerve/tissue interactions in the colony-stimulating factor-1 deficient osteopetrotic mouse. Dev Dyn 211:52-59

Naito M, Takahashi K (1991) The role of Kupffer cells in glucaninduced granuloma formation in the liver of mice depleted of blood monocytes by administration of strontium-89. Lab Invest 64:664-674

Naito M, Wisse E (1977) Observations on the fine structure and cytochemistry of sinusoidal cells in fetal and neonatal rat liver. In: Knook DL, Wisse E (eds) Kupffer cells and other sinusoidal liver cells. Elsevier North Holland Biomedical, Amsterdam, pp 497-505

Naito M, Yamamura F, Takeya M, Takahashi K (1986) Ultrastructural analysis of Kupffer cell progenitors. In: Kirn A, Knook DL, Wisse E (eds) Cells of the hepatic sinusoid, vol 1. Kupffer Cell Foundation, Rijswijk, pp 13-20

Naito M, Yamamura F, Nishikawa SI, Takahashi K (1989) Development, differentiation and maturation of fetal mouse yolk sac macrophages in cultures. J Leukoc Biol 46:1-10

Naito M, Takahashi K, Nishikawa SI (1990) Development, differentiation and maturation of macrophages in the fetal mouse liver. $\mathrm{J}$ Leukoc Biol 48:27-37

Naito M, Hayashi SI, Yoshida H, Nishikawa SI, Shultz LD, Takahashi K (1991) Abnormal differentiation of tissue macrophage populations in "osteopetrosis" (op) mice defective in the production of macrophage colony stimulating factor. Am J Pathol 139:657-667

Naito M, Umeda S, Yamamoto T, Moriyama H, Umezu H, Hasegawa G, Usuda H, Shultz LD, Takahashi K (1996) Development, differentiation, and phenotypic heterogeneity of murine tissue macrophages. J Leukoc Biol 59:133-138 
Nakakura-Ohshima K, Watanabe J, Kenmotsu S, Ohshima H (2003) Possible role of immunocompetent cells and the expression of heat shock protein-25 in the process of pulpal regeneration after tooth injury in rat molars. J Electron Microsc 52:581-591

Nakamura M, Bringas P Jr, Nanci A, Zeichner-David M, Ashdown B, Slavkin HC (1994) Translocation of enamel proteins from inner enamel epithelia to odontoblasts during mouse tooth development. Anat Rec 238:383-396

Ohshima H, Sato O, Kawahara I, Maeda T, Takano Y (1995) Responses of immunocompetent cells to cavity preparation in rat molars: an immunohistochemical study using OX6monoclonal antibody. Connect Tissue Res 32:303-311

Rutherford MS, Witsell A, Schook LB (1993) Mechanisms generating functionally heterogeneous macrophages: chaos revisited. J Leukoc Biol 53:602-618

Sawa Y, Horie Y, Yamaoka Y, Ebata N, Kim T, Yoshida S (2003) Production of colony-stimulating factor in human dental pulp fibroblasts. J Dent Res 82:96-100

Soranzo MR, Koerten HK, Daems WT (1978) Peroxidase activity and morphometric analysis of alveolar macrophages in guinea-pigs. J Reticuloendothel Soc 23:343-359

Takahashi K, Yamamura F, Naito M (1989) Differentiation, maturation and proliferation of macrophages in the mouse yolk sac: a lightmicroscopic, enzyme-cytochemical, immunohistochemical, and ultrastructural study. J Leukoc Biol 45:87-96

Takashima A, Edelbaum D, Kitajima T, Shadduck RK, Gilmore GL, Xu S, Taylor RS, Bergstresser PR, Ariizumi K (1995) Colonystimulating factor-1 secreted by fibroblasts promotes the growth of dendritic cell lines (XS series) derived from murine epidermis. J Immunol 154:5128-5135
Tsuruga E, Sakakura Y, Yajima T, Shide N (1999) Appearance and distribution of dendritic cells and macrophages in dental pulp during early postnatal morphogenesis of mouse mandibular first molars. Histochem Cell Biol 112:193-204

Vassiliou I, Lolis E, Nastos C, Tympa A, Theodosopoulos T, Dafnios N, Fragulidis G, Frangou M, Kondi-Pafiti A, Smyrniotis V (2010) The combined effect of erythropoietin and granulocyte macrophage colony stimulating factor on liver regeneration after major hepatectomy in rats. World J Surg Oncol 8:57-62

Wisse E (1974) Kupffer cell reactions in rat liver under various conditions as observed in the electron microscope. J Ultrastruct Res 46:499-520

Widmann JJ, Fahimi HD (1975) Proliferation of mononuclear phagocytes (Kupffer cells) and endothelial cells in regenerating rat liver. Am J Pathol 80:349-366

Yamada M, Naito M, Takahashi K (1990) Kupffer cell proliferation and glucan-induced granuloma formation in mice depleted of blood monocytes by strontium-89. J Leukoc Biol 47:195-205

Yamamoto T, Kaizu C, Kawasaki T, Hasegawa G, Umezu H, Ohashi R, Sakurada J, Jiang S, Shultz L, Naito M (2008) Macrophage colony-stimulating factor is indispensable for repopulation and differentiation of Kupffer cells but not for splenic red pulp macrophages in osteopetrotic (op/op) mice after macrophage depletion. Cell Tissue Res 332:245-256

Zhang J, Kawashima N, Suda H, Nakano Y, Takano Y, Azuma M (2006) The existence of CD11c+sentinel and F4/80+ interstitial dendritic cells in dental pulp and their dynamics and functional properties. Int Immunol 18:1375-1384 